\title{
The Economics of the Supreme Court's Decision On Forward Looking Costs
}

\author{
GREGORY L. ROSSTON* \\ Stanford Institute for Economic Policy Research \\ and \\ ROGER G. NOLL \\ Economics Department, Stanford University
}

\begin{abstract}
In May 2002, the Supreme Court upheld the rules promulgated by the Federal Communications Commission (FCC) to implement provisions in the Telecommunications Act of 1996 (the Act) regarding mandatory resale of the components of local telephone networks. This article explains the background of the forward-looking pricing rules adopted by the FCC, the economic rational for their use, and the implications of the Court's ruling for the future of local telecommunications competition.
\end{abstract}

\section{Introduction}

In May 2002, the Supreme Court issued an important decision on the FCC's rules about pricing and provisioning the components of local telephone networks for local service entrants that seek to resell part but not all of an incumbent's local network. This article examines and evaluates the economic implications of the Court's decision.

Section 2 of this article discusses the pricing provisions of the Telecommunications Act of 1996. Section 3 analyzes the FCC's decision to implement these provisions by adopting forward-looking costs as the basis for pricing network components. Section 4 discusses the Court's decision as well as two dissents from this decision. While this section concludes that the majority was correct in determining that the FCC's rules were a reasonable method for carrying out the provisions in the Act, it also concludes that this decision leaves unresolved an important contentious issue: the precise nature of the obligation of incumbent carriers to assist entrants in combining network components. Finally, Section 5 examines the implications of the Court's ruling for the future of local telecommunications

\footnotetext{
* Contact author. Mailing address: Stanford Institute for Economic Policy Research, Stanford University, Stanford, CA, 94305, U.S.A. E-mail address: grosston@stanford.edu. Both authors participated in the promulgation of the FCC rules, Rosston as Deputy Chief economist at the FCC and Noll as providing amicus comments. Since then Rosston has advised various government agencies, ILECs, CLECs, and IXCs and on the implications of the FCC rules.
} 
competition. In our view, the Court's decision is unlikely to harm consumers, and could benefit them if it facilitates the emergence of real competition and eventually deregulation in local access service.

\section{The Telecommunications Act of 1996}

A major stated purpose of the Act was to open local telecommunications access markets to competition. The settlement of U.S. v. AT\&T in 1984 separated the Regional Bell Operating Companies (RBOCs) from the manufacturing and long distance components of AT\&T, and prevented the RBOCs from entering either of these markets. One premise of the line-of-business restrictions on RBOCs was that local access was likely to remain largely monopolized because competitors faced significant entry barriers to becoming serious players in local services. The Act sought to break down these barriers and thereby to create sufficient local competition to allow the RBOCs to be freed from these restrictions.

Unfortunately, the Act was a mish-mash. One member of Congress quipped to Reed Hundt: "How'd you like that Act we gave you? We put everything in it. Then we put its opposite in." While humorous, this quip signalled that endless litigation was about to commence over the parts of the statute that were opaque or inconsistent.

While masquerading under deregulation, the buzz-word du jour, the Act created an elaborate labyrinth of regulatory rules and called upon the FCC to issue implementing regulations within six months after its passage. The recent Court decision, six years later, deals with only some aspects of the first wave of implementing regulation, and so, late as it is, the recent Supreme Court decision will not end the wrangling about the Act - at best, it resolves one important but small part of the controversy over the its implementation.

The Act requires that RBOCs open their local networks to competitors. In return, if an RBOC satisfies a 14-point checklist about the openness of its local markets in a particular state plus a vaguely worded "public interest" standard, it can receive permission to enter long distance in that state. The FCC rejected most of the initial requests by RBOCs to enter long distance, but in more of the recent cases, RBOCs have satisfied the competitive checklist and received long distance approval. Many more long distance entry approvals are expected by the end of 2003.

In order to satisfy the requirement that local markets are open to competition, a state's regulators and its RBOC must allow competitors to enter in each of three ways: build their own local access networks; buy the incumbent's local services at wholesale and rebrand it for retail resale; and create a hybrid network that combines some of the entrant's facilities with unbundled network elements ("UNEs") that are acquired from the incumbent. Because entrants are unlikely to succeed if their customers can not call and be called by customers of the incumbent at a reasonable price, RBOCs are required to interconnect with their competitors and to agree to cost-based reciprocal payments for terminating calls on another network.

Industry participants have fought over all aspects of these requirements, including the technical details of interconnection requirements, whether calls to Internet service providers qualify for reciprocal compensation, and the gap between wholesale and retail prices for firms that seek to enter as resellers; however, the recent Supreme Court case deals only with the requirement to offer UNEs to entrants in local access service. The only 
issues addressed in this case were how UNEs should be priced, and whether incumbent local exchange carriers were required to perform the technical work of combining UNEs for competitors that sought to buy more than one.

UNEs are the piece parts of the local telephone network - the copper wire (local loop) between a customer and the local switch, the electronics at each end of the loop that connect the copper wire to either the customer's internal wiring or the local switch, the local switch itself, transport between local switches, information processing functions inside the local switch, etc.

Initially the FCC required incumbents to divide the local network into seven different UNEs, but the number remains in dispute and could either shrink or grow, depending on which functions and physical components are defined to constitute basic local access. The Act requires that competitors be allowed to buy any number and combination of these UNEs to construct their own local network, but is unclear about whether incumbents or entrants are responsible for combining these elements in cases in which a competitor seeks to acquire more than one UNE but less than the complete local access service, including switching.

\section{The FCC implementation of the Act - TELRIC pricing}

In the absence of a voluntary agreement between an incumbent and an entrant (which rarely occurs), the Act directed the FCC to develop guidelines for pricing UNEs "based on the cost (determined without reference to a rate-of-return or other rate-based proceeding) of providing the interconnection or network element (whichever is applicable)..." Based on these guidelines, each state regulator determines the prices for UNEs within that state.

The FCC could have adopted a variety of different methods to implement the Act's mandate, including a version of historical costs, forward looking costs, or the efficient component pricing rule. The FCC settled on the use of forward looking economic costs to price the network elements. The FCC invented a new term, Total Element Long Run Incremental Cost (TELRIC), for its costing method. According to the TELRIC method, the price of a UNE should be based on the cost of building an efficient network using the best available technology, rather than the actual cost of the incumbent's network (or any other network that was built in the past). The FCC's rationale for TELRIC is that it replicates pricing in competitive markets: just as older computers are worth less when newer, better computers are introduced, the price of UNEs, if they were competitively supplied, would reflect the costs of the firms that supplied these elements most efficiently.

Incumbents argue that this method leads to prices that are too low, and so will not allow them to recover past investments prudently incurred or the cost of future risky investments. The economic basis for this argument is as follows. In competitive markets in which technology is advancing rapidly, the first firm to adopt a cheaper technology typically enjoys a period in which its price exceeds its average cost. The first firm to innovate, therefore, enjoys super-competitive profits until other firms copy the technology and the process of price competition begins to erode the innovator's profit margin. This period of extra profits provides the incentive for firms to engage in the research and development that leads to cost-reducing innovation. Based on this argument, the RBOCs argue that UNE prices should be based on historical or forward-looking actual costs. 
Proponents of TELRIC accept this argument; the disagreement is about whether TELRIC prevents innovative firms from being rewarded for their innovations and forces others to drop their prices below their own costs. To clarify this disagreement, all pricing methods that are based on cost boil down to a version of the same formula:

$$
\mathrm{C}=\mathrm{V}+\mathrm{K}(\mathrm{d}+\mathrm{i}+\mathrm{r})
$$

where $\mathrm{C}$ is the cost of a service that is to be recovered through pricing, $\mathrm{V}$ is the variable cost of the service (electricity, labor, etc.), $\mathrm{K}$ is the capital investment that the service uses, $d$ is the rate of depreciation of this investment, $i$ is the competitive return to a risk-free investment, and $r$ is the incremental risk adjustment to the return on investment that is the minimum additional return that is necessary to induce private investors to invest in the service. The two basic approaches to calculating costs are to use either a firm's actual cost experiences or to use some other benchmark. Traditional utility regulation has used some combination of a firm's actual historical costs and forecasts of its expected future costs to calculate C. TELRIC makes use of "best practice" costs within the industry.

The crux of the debate is about whether TELRIC prevents a firm from recovering reasonable investment costs, or $\mathrm{K}(\mathrm{d}+\mathrm{i}+\mathrm{r})$. The value of a capital investment falls as it ages for two reasons: it is "used up" in the sense that it requires more maintenance and repair to keep operational, and it becomes obsolete as newer technologies are introduced. The latter issue is the important one in telecommunications. Most telecommunications equipment (outside wires and switches) is physically operable for a very long period, but technological progress in the electronics of the network is extremely rapid. Thus, the primary concern in developing costing procedures in telecommunications is whether capital costs properly reflect the rate of technological progress and associated obsolescence. Obviously, if the components of the cost estimation are firms actual historical experiences and forward-looking cost estimates, prices that are based on these costs will allow the firm to recover its investments and earn a sufficient return to attract new financial capital. The issue is whether a formula that is not based on a firm's actual cost also can recover all of the firm's costs.

In principle, forward-looking cost models can accommodate the concerns of TELRIC's opponents by developing economically appropriated methods to take into account obsolescence in estimating depreciation (d) of capital investments and the risk adjustment (r) to the financial cost of capital. In estimating the costs of a service element, the depreciation term, $d$, should reflect the average expected experience of the investment with respect to wearing out and becoming obsolete. Among the factors determining the risk adjustment, $r$, is the chance that the rate at which the investment wears out and becomes obsolete departs from expectations. If depreciation and risk adjustment rates are calculated reasonably accurately, firms will be able to recover the costs of efficient investments. Thus, the TELRIC approach, theoretically, is able to cope with the problems that worry its opponents as long as the firm operates efficiently. Conceptually, historical costs should be identical to forward-looking costs if firms minimize costs and if true economic depreciation and risk adjustment rates have been used.

Pricing methods that are based on actual costs were used in the era of rate of return regulation, which the Act has explicitly disavowed. While TELRIC has many similarities with rate-of-return regulation, it does not base a firm's UNE prices on the firm's own 
behavior, so that incumbents, as in the case of price cap regulation, have a powerful incentive to minimize costs.

Some argue that TELRIC does not account for the "real options" effect: that investment immediately becomes sunk and irreversible so that entrants get a free ride on the risky investments made by the incumbents. This argument is based on an important and valid point: a mechanism to determine prices for UNEs must take account of the risk incurred by the provider of UNEs or the supply will dry up. An important part of an appropriately calculated forward-looking, efficient cost is the risk associated with building the network, as reflected in the risk adjustment, $r$. But this criticism is not a valid indictment of TELRIC principles. The FCC recognized this problem when it designed TELRIC, which includes risk adjustments in estimating the costs of an efficient network.

The debate about TELRIC is not really motivated by whether, in principle, prices based on TELRIC methods can appropriately reward innovation and risk. Instead, the root of the dispute is over whether incumbent local access carriers are entitled to recover the full costs of historical investments that were not efficient, not tailored to the provision of local access service, or were incorporated into prices using an economically incorrect method for estimating annual capital costs. If in the past RBOCs, perhaps to satisfy state regulators, used depreciation rates that were too low, and overbuilt their networks to pad costs (and hence recoverable profits), to provide unremunerative services, or to prepare for growth in other services, like broadband or long distance capacity, that did not materialize, the remaining unreimbursed embedded costs of the network will be higher than TELRIC costs.

Whether TELRIC would undermine the ability of RBOCs to recover their costs depends on two factors. The first is the magnitude of the unrecovered capital costs of RBOCs that would not be permitted into the calculation of UNE prices under TELRIC. The second is the extent of entry that is based on UNEs. Both are subject to considerable uncertainty. Even if UNEs are priced below the historical cost of local network elements, companies that seek to cobble together networks from parts of the incumbent's network and parts of their own may face offsetting costs (including business risks) that make hybrid entry an unlikely threat to incumbent local carriers. Nevertheless, the position of the RBOCs is understandable - TELRIC poses a risk, however small, of potential revenue losses that RBOCs would be able to recover under either the status quo or a system of higher prices based on actual embedded costs.

In principle, TELRIC could accommodate even this concern. The impact of the sunk and irreversible investment could be reflected in higher rates of depreciation and riskadjusted capital cost for a period of years until the RBOCs were fully reimbursed for their historical costs. These adjustments could reflect the actual experience of each RBOC, since both specific RBOCs and specific network elements plausibly have been subject to different errors in the ways state regulators calculated depreciation rates, risk adjustments, and capital expansion requirements. TELRIC could accommodate these differences by assigning different costs of capital to the different elements depending on the nature of those investments and their historical treatment.

Nevertheless, although these adjustments are consistent with TELRIC, they have a disadvantage as well. If UNE prices are too high (or too low), and if UNEs plausibly could become an important feature of successful local entry, then prices that make up for the errors of the past will distort the future development of competition in local access. Adopting a price for UNEs based on depreciation and risk adjustments that enable incumbents to recover uneconomic costs will lead to prices that overstate economic costs 
and send inefficient entry signals. Thus, if historically regulation has led incumbent local access carriers to invest in uneconomic capacity and to adopt excessively low depreciation rates, policy makers now face a genuine dilemma. Any pricing method that allows the mistakes of the past to be made up in UNE prices that are too high is inherently anticompetitive. (The efficient components pricing rule is a method for dealing with this issue in a manner that reduces the distortion and anticompetitive effects from using service prices to recover uneconomic costs; however, it simply seeks to reduce the social cost of reimbursing incumbents for their sunk costs, rather than resolving the dilemma). The FCC attempted to deal with this by requiring a competitively neutral fee to make up for any embedded costs that are not paid for through a combination of ILEC wholesale and retail sales.

As is apparent from the preceding discussion, the FCC's guidelines for forward-looking pricing leave considerable discretion to state regulators when determining actual UNE prices. States are responsible for determining the cost of capital, including both the rate of depreciation and an appropriate risk-adjusted, forward-looking financial return that will allow the incumbent to attract capital to make further investments. Nevertheless, the state's discretion is constrained by two requirements: the specific method for estimating costs must be accepted by the FCC as consistent with TELRIC principles, and, when challenged through legal appeals, must be approved by the courts as satisfying both the requirements of the Act and the FCC, and the general requirement that regulators not expropriate a firm's capital investments.

\section{The Court's decision}

The Supreme Court's decision dealt with the legality of the FCC's implementing regulations with respect to TELRIC pricing methods and the obligations of incumbent local carriers to provide assistance in combining UNEs. The pricing part of the case was decided on a 7-1 vote, with Justice Breyer dissenting. The part of the decision that dealt with UNE provisioning was decided on a 6-2 basis with Justices Breyer and Scalia dissenting. Justice O'Connor recused herself from the case.

Justice Breyer's dissent on pricing agrees with the claims of the RBOCs that incumbent local access firms cannot recoup their investments under the TELRIC formula. The dissent also argues that under TELRIC, entrants have no incentive to invest in their own network infrastructure if they are able to buy UNEs at prices equal to the cost of the most efficient network provider. The second dissent on whether incumbents are responsible for bundling separate UNEs was based on the "plain language" of the statute, which says that entrants can lease elements and combine the elements. The dissent argues that the statute does not require that incumbents must perform the combinations.

The Court majority rejected both dissenting arguments. The majority found that the TELRIC approach is consistent with a wide range of prices. Because state regulators are responsible for setting element prices, they have the authority to adjust the cost of capital to account for risk, depreciation rates to account for the advance of technology, and "fill factors" to account for growth in the network. The court majority found that nothing in TELRIC necessarily says that incumbents won't be fully compensated, nor that TELRIC will necessarily produce prices lower than historic cost. Moreover, should a state implement TELRIC in a manner that prevents full cost recovery, incumbents can appeal to 
both the FCC and the courts to reject these prices as expropriation. The Court also rejected the alternative pricing methodologies that the incumbents supported because the Court believed that they would have limited local telephone competition in ways that are not consistent with the Act. In the end, the Court concluded that the Commission has enough discretion to pick its version of forward-looking cost estimation over the others:

Whether the FCC picked the best way to set these rates is the stuff of debate for economists and regulators versed in the technology of telecommunications and microeconomic pricing theory. The job of judges is to ask whether the Commission made choices reasonably within the pale of statutory possibility in deciding what and how items must be leased and the way to set rates for leasing them.

The second major part of the Court's majority decision involved combining UNEs. Some competitors may want to use unbundled loops, others may want unbundled switching services, and still others may want both. The incumbents generally provide loop and switching services together so that "combining" them is the natural course of business for them. The FCC had ruled that incumbent local access carriers are responsible for combining UNEs if entrants cannot do it themselves. The question for the Court was whether the statute empowered the FCC to issue such a rule.

The economic argument put forth by the FCC and local access competitors was that it is usually more efficient for the incumbent to do the combining rather than to force entrants to do it. The FCC also said that the incumbent could charge a cost-based rate to do the combining. The incumbents argued that the language of the statute required that they had to allow entrants to combine elements, but that they did not have to combine them for their competitors.

The Court upheld the FCC's rule. The exact wording of that rule is as follows: "If the carrier is unable to combine the elements, the incumbent must do so." During the next year "unable" may become the telecom equivalent of "is" in that future policy hinges on its precise meaning. Right now, "unable" means that the competitors assess their own capabilities, and, if they decide that they are "unable" to combine UNEs, they can demand that local access carriers combine them, even if the incumbent does not combine them itself in its normal course of business. The question that will be the subject of future debate is what unable means. Does unable mean simply that a entrant bears the burden of proof that it is technically incapable of combining UNEs, or that it could not conceivably become capable if it hired enough technicians? Does unable apply when the competitor could do the job but is denied access to the network (an incumbent may be unwilling to allow others, including a competitor, to attach their own loops to the incumbent's switch)? Does unable hold when combination by the entrant, while physically possible, is simply so costly that entrants could not afford to base competitive networks on multiple UNEs without reliance on the incumbent to combine them?

\section{Implications for the future of local competition}

The immediate impact of the Court's decision is not likely to be large. Most states already have adopted TELRIC pricing principles for setting UNE rates; a decision the other way would have set more substantial change in motion, and significantly delayed implementation of the UNE requirement of the Act. The immediate impact is to resolve uncertainties for incumbents and new entrants about UNE pricing principles and provisioning requirements. 
Another important aspect of this decision is that not only has TELRIC been upheld as a pricing method, but the FCC and state regulators have retained a great deal of discretion over precisely what it means and how it will be implemented. The presence of discretion means that battles over the details of UNE rules are sure to continue in state regulatory commissions and, eventually, the FCC, which has the authority to block state pricing decisions if they do not conform to the Act and FCC rules.

The FCC is in the midst of reviewing which UNEs need to be provided to competitors by the incumbents. Predictably, the incumbents have proposed to limit the specific UNEs that they must provide, while their competitors have pushed to expand the scope and packaging of the UNEs. This proceeding is part of the "triennial review" of the elements "necessary" for competitors to be able to provide competitive local telephone service and of the meaning of the "check-list" that must be satisfied if incumbents are to be allowed to offer long distance service.

A recent District Court opinion rejected previous FCC rules that mandated national availability of elements. The FCC is likely to use this proceeding to address the remanded issues by setting up national standards to determine when an element must be unbundled, based on the availability of competitive alternatives in the geographic area. Even with such rules, a debate is likely to ensue about the extent to which the UNEs that incumbents must provide ought to vary geographically, and whether the presence of other forms of competition should be a factor in deciding whether incumbents must continue to offer specific UNEs. For example, if a firm faces competitors that combine the incumbent's local loop with the competitor's switch, can the incumbent discontinue providing the switching UNE?

Despite high-profile bankruptcies of companies like Northpoint and Rhythms, competitors have made some inroads into the local exchange market. But progress is slow, and much of it relies on UNEs. Excluding wireless telephones, as of June 2001 the FCC reported that competitors provided about $9 \%$ of local telephone lines. About 3\% were provided over their own facilities, about $2 \%$ were pure resale, and about $4 \%$ used UNEs. Of the competitors making use of UNEs, more than half combined loops and switches (UNE-platform or UNE-P). According to the FCC, UNE-P was the fastest growing segment of the competitors' lines.

The Court's decision makes the UNE-P alternative more stable; however, it does highlight the question about the future of facilities-based competition - will competitors choose to rely on regulated rates for UNEs or use UNEs as a stepping stone to start local networks that eventually will be full, facilities based competitive systems? This question is high on the list of concerns for the FCC. Competitors argue that they are making substantial investments in their own facilities and are using UNEs as a stepping stone to their own facilities. The incumbents argue that competitors have no incentive to build their own facilities while they get a free ride on the risky investments made by the incumbents. Still another possibility is that, because of the growth of wireless technology, no competitor will ever build a large, wire-line local network regardless of the regulatory rules. If so, the investment incentives for competitors created by the FCC's UNE rules are irrelevant.

Due to the Court's decision, the FCC undoubtedly will continue to require that incumbents provide at least some UNEs at TELRIC rates. Thus, the decision permits a test of whether the stepping stone theory of local access entry is valid. While the outcome of this experiment is uncertain, two possible outcomes are likely to be good for consumers. One is that facilities-based competition in wire-line access, with entrants eventually 
providing switching and other intelligent network functions, emerges from UNE-based entrants. The second is that wireless services make local telephone access competitive even if wire-line competition remains very limited. In either case, local access regulation can be replaced by competition.

The third possible outcome is that when the dust settles, most local access competition will take the form resale of the incumbent's facilities. In this case, consumers are not likely to benefit, and regulation will, if anything, grow as regulators are called upon to resolve disputes between incumbents and resellers. For reasons argued in this essay, we agree with the Court that a fourth conceivable outcome, to drive incumbent carriers to bankruptcy and to retard local access investment, is certainly easily avoidable and implausible within the context of the FCC's TELRIC rules.

Had the Court ruled the other way, the only option eliminated would have been the possibility for UNE-based entry that is a stepping stone to facilities-based competition, based on either full parallel networks or alternative networks that combine resale of local loops with switching facilities that are provided by the entrants. Regardless of the Court's decision, the Act still requires that state regulators and local access carriers allow resale of local service, which, in the long run, provides little benefit to consumers. Thus, the Court's decision is unlikely to harm consumers, and could benefit them if it facilitates the emergence of real competition and eventually deregulation in local access service.

\section{$6 \quad$ References}

Federal Communications Commission (1996) Implementation of the Local Competition Provisions in the Telecommunications Act of 1996, CC Docket No. 96-98, First Report and Order, August 8 ("Local Competition Rules").

Rosston, G. (1997) "The Telecommunications Act Trilogy," Media Law and Policy . Vol V, No. 2 Winter, pp 1-12. http://www.cmcnyls.edu/public/MLP/TrilgWeb.HTM.

Supreme Court of the United States, Verizon et al v. FCC et al. (2002) Case No. 0051, May 13. 